\title{
Editorial
}

\section{Community Operational Research: Innovations, internationalization and agenda-setting applications}

\author{
Michael P. Johnson, Gerald Midgley \\ Special Issue Editors \\ Jason Wright, George Chichirau \\ Editorial Assistants
}

\section{Introduction}

For readers who have never come across Community Operational Research before, it has been variously described as "OR... for community development" (Midgley \& Ochoa-Arias, 2004, p.3), OR for "social purpose organisations" (White, 2018) and OR with "the meaningful engagement of communities" at its heart (Midgley, Johnson, \& Chichirau, 2018). We will not dwell on definitions and their implications for practice, as this is the focus of the first section of papers in this special issue. Suffice it to say, however, that community concerns are central to Community OR projects, whichever definition is preferred.

We are proud and excited to be introducing this special issue to you, for several reasons. First, the quantity, quality and diversity of the papers have all exceeded our expectations. Second, for us, this collection of papers exemplifies what it is possible for OR to aspire to in terms of both benefit to society and academic publishing. In the context of this last comment, we want to say something about how we approached our editorial role, which is consistent with our normative vision of OR.

\section{The editorial process: towards a normative vision of $O R$}

We received 90 proposals of potential papers in response to our special issue call - many more than expected. The quality of these was generally high: it was going to be difficult to decide which authors to invite to submit full papers to be sent to referees, and which to decline. We sat down to think through our selection criteria.

In our initial call, we had stipulated what we were looking for. In addition to reflections on the nature and purpose of Community OR, we were keen to publish reports of projects, but not just descriptive case studies: to be worthy of inclusion, a paper had to illustrate the value of a theoretical or methodological innovation that could be adopted or adapted in future projects. In other words, papers reporting projects had to offer some insights with the potential to be taken up by our wider research community. This is not unusual for academic journals to insist upon, and it formed our first criterion for selection. We then added 'quality of the argument' and 'clarity of the writing'. 
Next, our discussion of criteria moved to what we appreciated and what we found lacking in the OR literature. We both expressed our frustration that so many academic OR papers of a predictive or prescriptive nature offer methodological innovations without actually applying them in practice. While researchers may present sound arguments for the methodological foci of their papers, their modeling too often uses simulated data, or data adapted from elsewhere, in hypothetical case studies. Of course, it could be seen as a high bar to ask researchers to present real projects, but this seems to us consistent with our normative understanding of OR as intervention. By 'intervention', we mean modeling to inform real-world decision making, where we have to think carefully and often critically about what it means in a particular context to best serve clients, stakeholders and/or communities.

After talking it over, we made a decision to exclude from consideration for this special issue all papers proposing methodological innovations that did not describe actual interventions (for example, model-based changes in operations or strategy) on the grounds that, if the innovation has not actually been tested in practice (rather than on a hypothetical case study or using secondary data), the evidence of utility is too weak to merit publication. Indeed, we suggest (controversially perhaps) that a theoretically or methodologically elegant approach may look good on paper, but unless there is evidence that it can usefully inform decision making in a non-academic context, it has to remain a mere proposal for an innovation. We observe that a large number of these kinds of proposals are published, but it is not clear how many of them are subsequently utilized in actual OR projects, so their value is questionable. Of course we are not the first to call for a greater focus on OR applications (see, for example, Ranyard, 1997), but in our view it is time to raise the bar for the standard of evidence required to support the presentation of methodological innovations: at minimum, there should be case study evidence from one example of real-world practice. Elsewhere, various authors have discussed other characteristics of good quality evidence (e.g., Keys \& Midgley, 2002; Midgley et al., 2013; White, 2006; Ormerod, 2014), but here we will merely observe that it needs to be derived from the study of actual OR practice. If this requirement were routinely adopted by journals, we believe that it would not only enhance the value of the OR literature to practitioners, but would also provide an incentive for academics to remain engaged in practice throughout their careers, thus blurring the academic/practitioner distinction that seems to be an issue for both 'camps'.

Using the above criteria, we desk-rejected some of the paper proposals and subsequent manuscript submissions, and of course more were eliminated through the refereeing process. In total, 31 papers were accepted for publication, and they fell into two categories: a small number reflecting on the general nature and potential of Community OR (e.g., how it should be defined, how it may inform other branches of OR, how team-ups with other disciplines could be useful, etc.); and, as discussed above, the majority of papers set out to argue for the value of particular methodological innovations, drawing upon OR projects to illustrate.

Also of great importance to us in editing the special issue was diversity, inclusion and representation. One of us (Johnson) has been particularly engaged with these issues, both in the Institute for Operations Research and the Management Sciences (INFORMS) and at his university, and is familiar with debates pitting quality against diversity. We believe that OR is strengthened by a 
variety of voices, methodological traditions, application areas and analytic methods. Therefore, we chose not to rely solely on scientific quality as a criterion for inclusion.

We believe that this special issue provides an example of what a regular issue of any OR journal could look like if there was a general expectation that evidence from OR practice is required to support claims to innovation, and a diversity of OR traditions was respected. Many more real-world projects than usual are discussed, but this was always going to be the case after we decided on the exclusions mentioned above. More important, perhaps, is the way in which most of the projects are presented: in almost every case, the process of intervention with clients, stakeholders and communities is in the foreground, with analytical innovations being discussed within this context. This reflects what every experienced OR practitioner knows: that analytical competence is necessary, but nowhere near sufficient to ensure a successful project - the most insightful analysis is of little or no value if it is not adequately addressing questions that are meaningful to clients and stakeholders. Likewise, if engagements with those clients and stakeholders are lacking or have broken down, trust in the analysis will be diminished. The process of intervention (or the process by which decision making is informed) is of central concern in OR practice, and many of the authors writing for this special issue focus on it in depth, in addition to presenting innovations in analytical methods. The process of OR is a vitally important topic for methodological learning in our research community (Keys, 1995).

This takes us onto making explicit another aspect of our normative vision for OR: the need to be able to deal with high levels of complexity. Some problems that the OR profession currently tackles in its practice are complicated rather than complex, meaning that they require analytical techniques to solve, but we can be confident that it is possible to find a best or optimal solution, and decision makers and stakeholders will accept it as such. This is not to say that complicated problems are trivial or unimportant, but organizations across the public, private and voluntary sectors are also increasingly wrestling with the kinds of 'wicked' (complex, multi-stakeholder, controversial) problem that were originally identified in a seminal paper by Rittel and Webber (1973). In our view, OR must not only engage with wicked problems, as it is already doing to an extent, but must think seriously about how it needs to transform its theory, methodology and practice in order to make these engagements more fruitful. This is not exactly a new refrain in our research community: almost four decades ago, Ackoff (1979a) issued a seminal call for expanding the mainstream remit of OR. As he pointed out, if we fail in this regard, we will find ourselves largely excluded from dealing with the most serious challenges in today's societies, such as a range of environmental issues that organizations across the sectors have to engage with (Midgley \& Reynolds, 2001, 2004). We suggest that this exclusion is already happening to an extent, but it is not too late to reverse the trend. Over the past four decades, it is mainly those parts of our research community specializing in problem structuring methods (e.g., Rosenhead \& Mingers, 2001), systems thinking (e.g., Midgley, 2003) and transdisciplinarity (e.g., Brown, Harris, \& Russell, 2010) that have kept the hope of dealing with wicked problems alive. However, these areas of methodology and practice are strongly marginalized in some places in the world (Mingers, 2011a, 2011b), and there is a real need to look, in every country, at how OR as a whole can be developed. 
To this end, we believe that tackling complex, controversial problems requires the sort of "enhanced OR" (Jackson, 1987, 1988, 2004) or "engaged OR" (Midgley et al., 2018) that deploys mixed methods for modeling in the context of methodological processes specifically designed to support multistakeholder engagement, collaboration, learning and intervention. Perhaps the most important argument for us, as we craft a normative vision for OR, is that you cannot know for sure whether a problem specification is controversial unless you ask stakeholders other than the client (Ulrich, 1993). This means that methodologies to structure the process of intervention are relevant to some degree in every project, if only to inform what kinds of upfront engagements to have, and with whom, to establish that a conventional OR approach will be adequate (Midgley et al., 2018).

We would like to see engaged OR (with engagements going beyond clients) being accepted as the norm in all branches of our discipline. This does not mean that the more traditional foci of OR practitioners on analytical techniques should be put to one side (we are not advocating a reduction of diversity). Rather, the development, deployment and subsequent adaptation of such techniques should be contextualized in relation to engaged OR and rich descriptions of the interventions using it.

\section{The internationalization of Community OR}

Earlier we said that the quantity, quality and diversity of the papers exceeded our expectations. Indeed, the diversity tells us a lot about how Community OR is evolving. While we could give a list of descriptive statistics covering many different features of the projects reported on in this special issue, we want to focus on just one significant observation: our specialism is rapidly being internationalized.

Historically, OR for community development has roots going back to the '60s and '70s in the UK and USA (e.g., Ackoff, 1970; Cook, 1973; Jones \& Eden, 1981; Noad \& King, 1977; Trist \& Burgess, 1978), although the term 'Community OR' itself was not coined until the mid-1980s (Ritchie \& Taket, 1994; Rosenhead, 1986). The label was used extensively in Britain for several decades before a parallel movement, with a different branding (Community-Based Operations Research), emerged in the USA (Johnson \& Smilowitz, 2007; Johnson, 2012). It was only towards the end of the 20th Century, and early in the 21st, that applications outside the UK and USA, often in developing countries, started to appear regularly (e.g., Barros-Castro, Midgley, \& Pinzón, 2015; Foote et al., 2007; Midgley et al., 2007; Ochoa-Arias, 1994, 2004; Rosenhead, 1993; Shen \& Midgley, 2007; Sova et al., 2015; Thunhurst, 2013; Tirivanhu, Matondi, \& Sun, 2016; Velez-Castiblanco, Brocklesby, \& Midgley, 2016; Waltner-Toews et al, 2004; White, Smith, \& Currie, 2011). Even as late as 2004, Midgley \& OchoaArias, 2004 were able to make the claim that international development was a new application area for Community OR practitioners, with a relatively small number of people involved at that time.

It is striking that, between 2004 and 2018, Community OR has been extensively internationalized. The evidence for this is in the special issue, with nine papers reporting applications in developing countries: specifically Bangladesh (Burns, 2018; Gomes, Hermans, \& Thissen, 2018), Colombia (Espinosa \& Duque, 2018; Pinzon-Salcedo \& Torres-Cuello, 2018), India (Burns, 2018), Kenya (Mwiti \& Goulding, 2018), Myanmar (Burns, 2018), Nepal (Burns, 2018; Helfgott, 2018), Nigeria (Ufua, 
Papadopoulos, \& Midgley, 2018) and South Africa (Romm, 2018). In addition, there are 7 papers reporting interventions in developed countries outside the UK and USA: Cyprus (Laouris \& Michaelides, 2018), Germany (McKenna, Bertsch, Mainzer, \& Fichtner, 2018), Finland (Konsti-Laakso \& Rantala, 2018), Italy (Ferretti \& Gandino, 2018), Japan (Goulding, Kelemen, \& Kiyomiya, 2018) and New Zealand (Brocklesby \& Beall, 2018; Morgan \& Fa'aui, 2018). Taken together, these applications outnumber those undertaken in the UK and USA. We therefore conclude that this special issue marks a watershed moment: while the UK and US traditions have historically been strong (and still are), we can no longer assume that researchers in these countries will remain the ones to craft the dominant narrative about what we do. As Community OR has become a truly global movement, there are now real opportunities for researchers outside the UK and USA to assume leadership, and for these two countries to be decentered in its further development. Community OR has transcended its geographical origins.

\section{Structuring the special issue}

Below, we explain how we have divided this special issue into sections. We start with (re)definitions of Community OR. This first section is like a funnel, drawing on the history of ideas and breadth of practices in our field to either consolidate or redefine our understanding of Community OR. We then move into a set of theoretical and methodological innovations, all of which are supported by examples from practice. Next, there are four sections about different substantive application areas: preventative projects with youth; working with indigenous communities; urban community development and planning; and rural development. The final section is on new frontiers and emerging trends in Community OR, plus interfaces with other practices and disciplines. This last set of papers is like an inverted funnel, taking the ideas presented in the rest of the special issue and looking at the wide range of different possibilities for their future development, as well as synergies with and potential influence upon other fields.

However, a caveat is needed. Many of the papers could have been placed in two or more sections, and we have positioned them according to what we perceive as their dominant characteristic or most significant contribution. More details are provided below.

\section{5. (Re)defining Community OR}

The special issue begins with four papers that, amongst other things, seek to define or redefine Community OR.

The opening paper, by Midgley et al. (2018), discusses the diversity of Community OR theory, methodology and practice, and points out that almost all authors over the years have avoided defining it - often because they have not wanted to inadvertently exclude or marginalize other people in our research community. This has resulted in a loss of clarity on what Community OR actually is, although because issues of relevance to communities often cut across the boundaries of third sector, public and private sector organizations, it is not a reasonable proposition to return to the 1980s assumption that Community OR is just projects with grass-roots community groups and charities. Midgley et al. (2018) argue that Community OR can be redefined as "modeling for intervention", involving "the meaningful engagement of communities". This, they suggest, has 
always been an implicit principle in our practice, so actually making it definitional does not bring unwelcome exclusions. It also helps us take positions on four controversies that have been discussed for decades in our research community: whether or not Community OR should be more explicitly political; whether it should be grounded in the theory, methodology and practice of systems thinking; the similarities and differences between the UK and US traditions; and whether or not Community OR offers an enhanced understanding of practice that could be useful to OR more generally.

The second paper, by White (2018), returns for inspiration to the work of Steve Cook, who was a post-war pioneer in the UK of the idea that the benefit from OR should be experienced by wider society and not just within the boundaries of the organizations using it (Cook, 1973). He was particularly critical of the kind of instrumental OR practice that maximizes organizational or shareholder gain at the expense of wider social well-being (for a collection of Cook's writings, see Bowen, Cook, \& Luck, 1984). White not only argues for the continuing contemporary relevance of these ideas, but also says they can help us redefine Community OR as OR for "social purpose organisations". He is careful to define a social purpose organization in a broad manner, so it can be a coalition of interests across the public, private, voluntary and community sectors, and does not have to be legally constituted as an organization. In the USA, these coalitions are often referred to as 'civic associations' (see, for example, Davenport \& Skandera, 2003). Having proposed this redefinition, White (2018) then goes on to look at its implications for measuring the impacts of social purpose organizations - a second substantive contribution.

Next we have a paper by Brauer (2018) that could have been included in the theoretical and methodological innovations section, but we have placed it with the 'definitional' papers because it argues against Midgley et al. (2018) on a crucial point of principle. Midgley et al. (2018) say that Community OR may be usefully defined in terms of "the meaningful engagement of communities", but they also say that non-community-engaged OR can be perfectly legitimate if no community concerns are at stake. Brauer disagrees with this and offers a political perspective, arguing that ultimately communities should have veto rights over the activities of public and private sector organizations when they believe that damage could be done. In this sense, all OR should be Community $\mathrm{OR}$, and practice that does not engage stakeholders and communities (beyond clients) is problematic. In addition, Brauer offers a systems model of 3D Community OR (or 3D-COR for short), partly based on this normative proposition, but also offering a framework to analyze forms of imprecision (concerning claims of a quantitative, qualitative or ethical nature) in statements about problematic situations. He uses examples of statements made in the context of a recent national doctors' strike in the UK to illustrate the framework's value to OR projects, and also explains how it helps to show the shortcomings of the Logical Framework (or 'Logframe') Approach (e.g., NORAD, 1999), which is very widely used for planning and evaluation in international development (Cracknell, 2000): the Logframe Approach assumes linear rational planning, whereas 3D-COR (like other approaches informed by systems thinking and complexity science, such as McEvoy, Brady, \& Munck, 2016) takes account of feedback processes and unforeseen circumstances.

This section then ends with a very different, and ambitious, contribution to redefining Community OR. Yearworth and White (2018) say the time has come to recognize that online communities are 
'communities' just as much as geographically co-located ones. However, online dialogue does not require a facilitator: social media platforms already provide sufficient structure ('scaffolding') for self-organizing communities dealing with issues that concern them to manage their own decisionmaking processes. Yearworth and White are critical of the practitioner-centric assumptions that are widely made in the Community OR literature, and argue for self-organization to be seen as the defining feature of communities. On this basis, Community OR is a spontaneously emerging phenomenon whenever communities use social media to scaffold their explorations of problematic issues and decision making responses. The traditional role of the practitioner is redundant in online communities.

It would be an abuse of our editorial role to take sides in this four-way debate about defining Community OR. We just want to acknowledge that this debate has been taken much further than we were expecting when we first started work on this special issue, and we encourage you to read the different contributions and make up your own minds.

\section{Theoretical and methodological innovations}

The first paper in this second section, on theoretical and methodological innovations, carries forward the theme of self-organization discussed in the previous contribution. Herron and Mendiwelso-Bendek (2018) ask how Community OR practitioners can best support the informal learning of self-organizing communities. They give two in-depth case studies of their own practice of supporting the construction of community conversations, and also reflect on the wider issue of better understanding the role of university-community partnerships.

Next is a discussion, by Hindle and Vidgen (2018), of their development of a new business analytics methodology (motivated by systems thinking, problem structuring, Community OR, data science and decision science) that enables people to develop a multidimensional view of business practice. The methodology is composed of a top-down analysis process that focuses on the business model of an organization (in this case a charity managing foodbanks), and it seeks to develop a business analytics portfolio. It offers a bottom-up approach to doing analytics that is grounded in data, tactical work, model building and technology. The authors apply the business analytics methodology to the planning and management of the Trussell Trust, which operates the largest foodbank network in the UK. The result is a re-imagining of what a business can do, using tools such as rich picture diagramming, business model mapping, activity model design, business model canvas and empirical data analysis to generate a range of potential analytics initiatives that help meet the client organization's fundamental value proposition.

The focus of the third paper in this section, by Helfgott (2018), is the concept of resilience and its implications for Community OR practice. While resilience has mostly been explored in relation to how ecosystems respond to significant disturbances, such as fires and floods (e.g., Gunderson \& Holling, 2002), it has also been used in the context of social systems, such as organizations and communities. However, when we discuss the latter, it is often not enough just to look at whether and how communities can 'bounce back' following adversity, as this assumes it is acceptable to return to the status quo. Instead, people might express resilience by inventing a new, more desirable 
future for their community. If Community OR practitioners are going to offer support for this, Helfgott argues that they can benefit from drawing upon the theory of boundary critique (e.g., Midgley \& Pinzón, 2011; Midgley, Munlo, \& Brown, 1998; Ulrich, 1994), which emphasizes the need for questioning: we always have to ask, "resilience of what, to what, for whom, over what time frame?" She gives detailed examples from her practice in Nepal to illustrate how community resilience can be enhanced, accounting for a wide range of economic, social and ecological issues.

The following paper, by Burns (2018), is critical of much international development practice for working mainly with town and village leaders and failing to engage with the poorest and most marginalized communities. He argues that Community OR practitioners should not only properly consider issues of marginalization, but they also need to learn how to scale up participation. This is important if an intervention is to have a wide systemic impact. Burns presents three interventions (in Bangladesh, Myanmar, India and Nepal), involving marginalized participants such as people with disabilities, slaves and bonded laborers, and reflects on the methodological learning in each participative exercise that allowed the subsequent one to be significantly scaled up. In each case, Burns shows how the participants developed insights into the systemic patterns that were trapping them in poverty and marginalization, which was essential for taking effective action. This is important because it is often assumed that scale of participation and depth of critical analysis are inversely related: we can either have widespread but superficial discussion, or participation needs to be restricted to a small group if we want in-depth insights. Here, Burns offers a set of methodological ideas that can help us to square the circle: it really is possible to develop meaningful systemic insights at scale.

Likewise concerned with marginalization in international development, Mwiti and Goulding (2018) set out to offer support to women's collectives ('Chamas') in Mwiti's original home country of Kenya. This and the next paper both provide examples of work in developing countries where Community OR methodologies and methods are integrated into larger social science projects: some aspects of these projects are primarily ethnographic (learning about the lived experiences of the participants), while others support self-organizing community groups in their decision making and actions. In respect to the former, Mwiti and Goulding follow Romm (2015), who argues that even traditional social science methods used in ethnographies (like interviews, surveys and focus groups) can be transformative if they privilege the voices of marginalized individuals and communities, and give them space for reflection and dialogue so they can develop new insights (also see Romm, 2018).

It is notable that Mwiti and Goulding have contributed the only paper in this special issue with a substantive gender focus, and it is strongly informed by feminist theory and understandings of intersectionality (how power relations construct multiple, interrelated forms of oppression and disadvantage). Given that most Community OR practitioners have a concern for social justice, it is rather surprising that gender has only been the focus of a small number of previous projects and publications (e.g., Taket, 1994; Lewis, 2016; Stephens, 2012, 2013), and we look forward to new developments in future work. 
Like the previous authors, Goulding et al. (2018) integrate a Community OR intervention into a larger social science project, but this time in the context of the community-based response to the 2011 Japanese tsunami. An important contribution in their work is the use of arts-based methods. There has been a long association between Community OR and problem structuring methods (Jackson, 1988), and the latter have often been portrayed as tools for qualitative 'rational analysis' that are complementary to mathematical problem-solving techniques (e.g., Rosenhead \& Mingers, 2001). Given that many in our discipline strongly value quantification, sometimes even to the exclusion of problem structuring methods (Ackermann, 2012; Ackermann et al., 2009; Mingers, 2011a, 2011b; Simchi-Levi, 2009), we suggest that terms like 'rational analysis' have been important to legitimacy in our research community. We suspect that arts-based methods have been marginalized in the past because they explicitly draw upon other ways of knowing than the rational-analytic to inform community insights (Rajagopalan \& Midgley, 2015). Given that other research communities, such as action researchers (e.g., Heron \& Reason, 1997; Liamputtong \& Rumbold, 2008), have no such concerns over the legitimacy of arts-based methods, and this paper by Goulding et al. (2018) demonstrates their utility for community empowerment in our own field, we argue that it is time to take them more seriously and look at how they can usefully be incorporated into our practice.

The next paper, by Gomes et al. (2018), examines the relevance of institutional theory to Community OR. They say that an institution is a set of "rules that structure behavior and interactions in society". They argue that, if institutional analysis is omitted from Community OR projects, there is a danger that key elements of problematic situations may remain invisible - specifically those elements that make systems resistant or amenable to change. After explaining the theory, and showing how it can be operationalized methodologically, Gomes et al end their paper with a case study of a Community OR project in Bangladesh illustrating the value of the theory to practice.

From Bangladesh, we move to Cyprus. Laouris and Michaelides (2018) outline the Structured Democratic Dialogic Process (SDDP), which is a widely-applied systems approach originally developed by Christakis (1996), Warfield (1973) and others. This is well known in the fields of systems thinking and systems engineering, but has not had quite the same degree of exposure in OR journals. SDDP is designed specifically to construct a dialogue using a modeling process that can be regarded as fair by all the participants, and it integrates ideas from multiple stakeholders into a shared understanding of both the problematic situation and how to take action in response. In their paper, the authors not only explain the history and current state of the art of SSDP modeling, but they illustrate the value of the approach by showing how it was used to facilitate a major, participative local government reform initiative in the Greek sector of Cyprus. Difficult issues were tackled, such as corruption. We suggest that SDDP could well have more general utility for Community OR projects.

Also taking a systems approach, Cabrera, Cabrera, Powers, Solin, and Kushner (2018) introduce the idea of a Complex Adaptive System (e.g., Gell-Mann, 1994; Merali, 2006) composed of "the networked interactions of individuals (agents) who adapt to and learn from an environment" (Cabrera et al., 2018). Consistent with this theory are a set of modeling tools to support systems thinking, collective organizing and stakeholder responsiveness. These tools are explained in detail by Cabrera et al, and their utility is illustrated with reference to several case studies of practice: one 
focused on water management and others on the community-engaged transformation of education across US school districts. The latter work touches on a theme that is common to several other papers in this special issue: intervention to empower youth, so the next generation is better equipped than their parents to think through and address the problems they encounter.

\section{Prevention is better than cure: working with youth}

Similarly picking up on the theme of working with the next generation, Pinzon-Salcedo and TorresCuello (2018) discuss a Community OR project in Bogotá, Colombia, where they worked with over 450 schools to introduce non-violent conflict resolution skills to students and their communities. The context was a 50-year civil war made worse by pernicious gang violence in the poorest, most marginalized communities. Pinzon-Salcedo and Torres-Cuello describe the project, which was designed using a combination of several different systems approaches, as "a grass-roots approach to peace-building". The idea was to give young people skills that would help them say 'no' when violence presented itself as an option. Thousands of volunteers were recruited to spread the message of peaceful conflict resolution, and within 6 years the programme had reached well over a million citizens. Pinzon-Salcedo and Torres-Cuello report findings from evaluations of the programme that show its knock-on or ripple effects. It is worth noting that this project has received several United Nations commendations and awards for impact on Latin American social development.

Also concerned with preventative action with youth, Taylor (2018) offers a novel adaptation of qualitative decision modeling, based on Interactive Planning (Ackoff, 1979b) and Value-Focused Thinking (Keeney, 1996), and she describes her application of this to the problem of the sex trafficking of children - specifically enhancing the ability of youth in Atlanta, Georgia, at risk of participation in sex trafficking, to make better decisions regarding personal relationships, resist the temptations of sex work, and rethink their beliefs about their future potential. The pilot implementation of the iSeeMe Society, described in the paper, provides a framework for engaging with vulnerable populations using Community OR and decision-theoretic principles in such a way as to improve capacity for personal decision-making.

Finally, on the theme of prevention being better than cure, Romm (2018) discusses her participation in a project with 500 South African schools to support marginalized youth in transforming narratives that restrict their life chances. Like Goulding et al. (2018) and Mwiti and Goulding (2018), Romm explains how traditional social science methods can be harnessed in the service of emancipatory intervention - but clarifies that the word 'science', as used here, shouldn't carry the connotation of researcher neutrality (for other comments on non-neutrality in values-informed inquiry, see Alrøe, 2000; Midgley, 2000, 2008; Romm, 2001; Ulrich, 1994; and Fazey, Schäpke, Caniglia, Patterson, \& Hultman et al., 2018). In addition, she discusses the importance of blurring the boundary between researchers and participants, so the former can legitimately act as agents of the latter, and participants can meaningfully inform the construction of Community OR projects (and we should note that this is also common in many action research approaches, as represented in Bradbury, 2015). Threaded throughout her paper is the theme of working from a "postcolonial Indigenous research paradigm" that emphasizes interconnectedness and the collaborative development of knowledge. Linked with this is the need to challenge 'deficit' narratives (i.e., disempowering 
narratives that emphasize what is lacking or problematic), many of which have their origins in colonialism, but still persist today.

\section{Working with indigenous people}

Romm's (2018) discussion of a "postcolonial Indigenous research paradigm" takes us on to three further papers that are specifically about working with indigenous people (the original inhabitants of a locality, before the arrival of colonizing forces). The first, by Morgan and Fa'aui (2018), introduces the mauri model: 'mauri' is the Māori (indigenous New Zealander) word for 'life force' or 'life supporting capacity'. Morgan and Fa'aui are Māori researchers, and they have developed a set of indicators for measuring life supporting capacity from a Māori perspective, using Māori concepts and values. Their paper situates their research in relation to the tradition of Kaupapa Māori, which is essentially research led by Māori for Māori, grounded in the Māori indigenous worldview and using culturally appropriate methods (also see Bishop, 1996, and Smith, 1999). Morgan and Fa'aui applied the mauri model to evaluate the remediation strategies that were being considered following New Zealand's worst maritime environmental disaster: the sinking of the ship, Rena, on a reef, 27 kilometers off the coast. Although this was a strongly community-engaged project, there was also another important dimension to it: the New Zealand Ministry for the Environment had called for restoration "of the mauri of the affected environment to its 'pre-Rena' state". As expertise on mauri lay with Māori, this meant Morgan and Fa'aui's project could inform government decision making, ensuring that the voices of the local tribe were heard.

Also based in New Zealand are Brocklesby and Beall (2018), whose paper considers "client and stakeholder engagement, and the alignment of methodologies and techniques with the sociocultural context of their application". They argue that research with indigenous people, when the researchers are not themselves indigenous, throws issues around engagement and the alignment of methods with the cultural context into sharp relief: the researchers cannot legitimately start by assuming that they know enough to engage appropriately, so they must be humble and open to learning if the project is to have any chance of success. Brocklesby and Beall suggest that this attitude of humility and openness to learning is likewise necessary for 'mainstream' Community OR. Their project illustrates what openness to learning in a different cultural context (in this case a Māori community) really means in practice.

Finally, on the subject of working with indigenous people, we have a paper by Espinosa and Duque (2018), who write about supporting the self-governance for sustainability of an Amazonian indigenous association in Colombia. Using a mixture of different systems approaches, and in particular the Viable System Model (e.g., Beer, 1984), the authors supported the participants in thinking through various paradoxes and dilemmas of self-governance so they could forge a collectively-agreed strategy for developing adaptive capabilities. In reflecting on their intervention, Espinosa and Duque then discuss various issues, including power relations and the difficulties of preserving an indigenous culture in a multi-cultural environment. 


\section{Urban community development and planning}

Urban community development and planning is a significant area in which Community OR is applied. First among the papers in this section is a discussion by Wang, Touboulic, and O'Neill (2018) of their project for improving access to affordable fresh food in a disadvantaged Welsh community. They used a problem structuring approach (drawing on multiple analytical methods, such as Qualitative Comparative Analysis, plus aspects of Soft Systems Methodology and Strategic Choice), and their innovation was to identify interventions that put the greatest possible emphasis on giving voice to the perspectives of affected community members. Indeed, they grounded their analysis in the lived experiences of community members, some of whom had limited use of the English language, much less an understanding of decision modeling concepts. They used a five-phase approach, involving extensive community engagement, to develop a suite of recommendations that could work at different scales and were based on various forms of social interaction. These addressed both necessary behavior change among residents as well as the need for new services to be offered by shops and government agencies. Most previous OR-based food security research has relied solely on quantitative decision modeling without much input from community members, and this paper represents a refreshing shift in approach.

Next, Konsti-Laakso and Rantala (2018) describe the development of a community engagement methodology influenced by writings in Community OR, facilitative modeling, problem structuring and innovation management. Their paper presents the theory and practice of stakeholder participation in decision making, and describes an application to a major city center redevelopment and restructuring project in Lahti, Finland. Importantly, the authors discuss the need for both divergent and convergent phases in group problem structuring to ensure that all stakeholder groups participate actively and effectively in formulating and setting local development priorities. Reflecting on their application, which used a new conceptual framework based on structured community participation, extensive dialogue in multiple focus groups and the use of brokers (researchers and planning professionals), the authors conclude that the business community and public servants were able to find sufficient common ground during the urban planning process to make an effective master plan possible. Also, all the community members, including members of marginalized groups, said the planning process was inclusive and productive.

Finally in this section, Fabusuyi (2018) describes a community intervention to reduce crime. However, instead of tackling crime head-on, Fabusuyi's project was concerned with the communityengaged redevelopment of affordable housing to improve informal social controls. A communitybased organization in Pittsburgh, USA, designed a community development strategy that emphasized novel approaches to property management to enhance the level of engagement of residents with activities to improve local quality of life. The innovation in this paper can be found in the application of a mix of qualitative and quantitative Community OR methods to identify development strategies that are simultaneously sustainable, replicable and generalizable.

\section{Rural development}

In addition to the above three papers on urban development, there are three more focused on the particular challenges of working in rural locations. The first is by Thorsen and McGarvey (2018), and it explores the financial feasibility of providing dental services to low-income and uninsured 
residents of Montana, USA, using mathematical programming models developed in collaboration with a local non-profit organization. In rural areas of Montana, eligible residents are widely dispersed, requiring periodic visits by mobile clinics. In their project, the authors engaged closely with a variety of local stakeholders to formulate the problem (identifying modeling parameters and constraints) and critique the results of the modeling. In the American context, where there is inadequate health insurance coverage for most low-income populations (and little dental insurance for otherwise-covered elders), the authors found that demand far outstripped supply, and the strategies that served the highest number of patients most equitably were not financially sustainable. Thus, the study made the case for subsidies to meet an important social need most effectively.

However, we note that Thorsen and McGarvey (2018) engaged with community-based service providers but not their clients. They differentiate between the UK tradition of Community OR, which requires community engagement, and the US literature on Community-Based Operations Research (CBOR), which requires stakeholder engagement only. They align the paper with CBOR and not Community $O R$ in this regard. For our own part, we suggest that the pivotal community perspective that mattered to this project was glaringly obvious to the dental service providers: comprehensive, affordable coverage is better than partial, unaffordable provision. This was uncontested, and was used as a foundational assumption for the OR modeling. Midgley et al. (2018) suggest that, when particular stakeholder or community views are already well known because key people have contributed their views through other activities, the costs of further engagement may outweigh the benefits, and narrower boundaries for stakeholder and community engagement can be justified. Arguably, this applies to Thorsen and McGarvey's project. Only if one takes Brauer's (2018) normative stance, that communities should have the option of directly vetoing professional decision making that affects them, is the exclusion of communities always illegitimate. Here we have presented both sides of the argument, and leave it for readers to make up their own minds.

The second paper on rural development is by Ferretti and Gandino (2018). They present one part of a larger research project to design and evaluate strategic alternatives for the redevelopment of properties in the vineyard region of a new World Heritage site in northern Italy. This strategic design problem was challenging due to the presence of multiple stakeholders, conflicting social and economic needs, and the marginalization of rural communities by urban residents. This marginalization was partly a consequence of an on-going process of migration from the countryside to the cities. Ferretti and Gandino used Choice Experiments in partnership with stakeholders and the local community to generate a range of prioritized redevelopment alternatives for a set of abandoned properties. They were able to provide clear guidance to planners on solution strategies, and they communicated to leaders the importance of more general capacity-building for localized planning expertise and community engagement.

The final paper in this section, by McKenna et al. (2018), describes the use of public workshops to build a multi-criteria decision model to identify and rank strategic alternatives for energy generation in a small rural German town. These workshops also provided data for, and used the results of, a sophisticated energy system investment and dispatch optimization model to generate alternatives that reflected local values, resources and technologies. The resulting strategic alternatives were 
evaluated in relation to three social objectives. By looking at the trade-offs in performance across these objectives, and by assigning weights generated in the public workshops, the authors were able to present a robust picture of community preferences. This paper represents a novel way to perform research that is both rooted in principles of community engagement and is mixed-method (qualitative and quantitative). Importantly, the authors took great care to express the results of the project in ways that could be easily understood by community members who knew little or nothing about OR (also see Ritchie, 2004, who talks about the need for transparency when using quantitative methods with community groups).

\section{New frontiers, emerging trends and interfaces with other practices and disciplines}

Bringing this special issue to a close is a group of papers looking to the future in different ways: some identify new frontiers and emerging trends in Community OR, some discuss the potential for synergies with other forms of research (beyond OR), and one advocates a strategic alliance with other intervention-orientated research communities to promote our common interests.

The first of these papers, by Gregory and Atkins (2018), examines the possible synergies that could come from bringing together Community OR and Citizen Science. Some versions of Citizen Science merely draft in the public to collect data for expert-led scientific projects, while others are more concerned with empowering citizens to undertake science in order to answer questions that matter to their communities. It is this second, more radical understanding of Citizen Science (e.g., see Irwin, 1995) that Gregory and Atkins argue aligns well with Community OR, given our emphasis on community engagement and empowerment. They also suggest that advocates of Citizen Science could learn from Community OR's use of problem structuring methods and other OR techniques, so that the science undertaken by citizens can more seamlessly feed into decision making. In this respect, they offer a practical case study of community involvement in promoting marine biodiversity. We agree with the authors that this appears to be a fruitful combination, and we look forward to further implementation in, and learning from, practice.

Switching attention to the strategic planning of public health services, Walsh, Kittler, and Mahal (2018) discuss the attempt of a Scottish regional health authority to import a Native American model of health care provision from Alaska, which emphasized strong community engagement and a preventative approach to common health problems. The latter model had been very successful in Alaska in both improving population health and reducing the cost burden of disease at a time when the latter was massively rising in other geographical areas. However, in Scotland, the new approach faced concerted resistance from doctors, who were expected to participate as equals in multidisciplinary teams (overturning the usual hierarchy of medical practitioners, with doctors at the apex). It was abandoned very quickly. The authors discuss the process by which the new model was introduced in Scotland, and they argue that the resistance came about because the health authority failed to account for how doctors perceived their own professional identities. Walsh et al then turn to what Community OR authors have said about how to address identity issues, and they specify 12 Community OR strategies that could have helped in Scotland, but were either not tried or were inadequately implemented. Their conclusion is that health governance organizations could usefully learn from Community OR, especially as the cost of healthcare is becoming unsustainable in many countries, so it is an imperative to develop new approaches. 
The next two papers are concerned with the role of business organizations. First, Ufua et al. (2018) examine how Lean practitioners aim to reduce waste in production processes to enhance value for both business organizations and their customers (see, for example, Womack \& Jones, 2003). Ufua et al argue that those using Lean can learn from the focus of Community OR on community engagement and critiquing the boundaries of intervention. Lean and Community OR might at first seem like an unpromising combination, but the authors demonstrate that synergies are possible, and they provide an example of a project working with a food production company and its local community in Nigeria. Via community engagement, the authors identified a waste management issue that was initially not mentioned by anyone in the company, but was causing real concern in the community: the dumping of animal effluent and remains near residential areas. Indeed, the growth aspirations of the food production company were being undermined because community representatives had brought in a governmental regulatory agency, which was threatening the company with continually increasing financial penalties. Working in partnership with the company and its local community, the authors and participants identified a win-win strategy, which would use the effluent to generate biogas; improve the reliability and cut the cost of energy supplies; increase food production; employ more local people; improve environmental health to the satisfaction of the local community; and enable the government regulators to ascertain that the company was meeting its legal obligations. The paper ends with reflections on the added value that Community OR can offer to Lean practitioners.

Like Ufua et al, Weaver, Crossan, Tan, and Paxton (2018) also discuss Community OR with business organisations. Their concern is matching charities embedded in local communities with business organizations wanting to support those charities. They identify a twin problem: businesses being inappropriately approached by too many charities that do not understand those businesses' charitable priorities; and charities being unable to effectively unlock the resources that business organizations actually want to make available. Their project in Scotland, which involved extensive problem structuring using a systems approach, generated the Connect Model to ensure better dialogue, alignment and co-creation of value between charities and businesses. Weaver et al present both their systemic process of engagement with stakeholders and the Connect Model itself. Both have the potential to be adapted for use elsewhere.

The next paper has a very different concern. Bammer (2018) argues that the Community OR practitioner community is just one amongst many research communities concerned with theories, methodologies and methods of intervention to deal with complex organizational, social and environmental problems. She points out that knowledge about good practice is fragmented across all these communities, with each one having its own preferred terminology and set of favored references. There is a tremendous opportunity for learning across these communities, and for Community OR practitioners to enhance their knowledge and resources through this learning, if only people would be willing to widen their boundaries of communication. Bammer (2018) is also concerned with the 'political' consequences of the fragmentation across our research communities, in terms of the continuing dominance in academia of the traditional disciplines which do not conceive of their activity in terms of intervention. While most of the long-established disciplines have professional societies with many thousands of members, and can therefore call on a critical mass of activists to work with governments, industries and other academic bodies to ensure their 
influence and sustainability, the intervention-orientated research communities are all too small for this. Thus, Community OR is in the same position as Systems Thinking, Action Research, Cybernetics, Transdisciplinary Studies, Implementation Science and many others: they all lack the necessary influence to consistently inform funding agendas, education policies and disciplinary assessment methodologies, so are at a perpetual risk of being marginalized. To deal with these problems, Bammer (2018) offers two solutions: first, a new 'discipline' of Integration and Implementation Sciences (12S), not to replace the many existing intervention-orientated disciplines, but to act as a conduit and repository for their knowledge to facilitate cross-community learning; and second, she calls for co-operation between all our intervention-orientated research communities to advance our common interest in moving from the margins to the mainstream. We believe the message for Community OR practitioners is worth taking seriously. Indeed, the wider professional OR community in the UK diminished in size during the latter half of the 20th Century (Fildes \& Ranyard, 1997). In the USA, the professional community grew between 2006 and 2016 (National Science Foundation, 2018), although it has changed dramatically in its branding in business schools and companies: from 'operations research' or 'management science' to, increasingly, 'analytics' and 'data science' (Liberatore \& Luo, 2010). Therefore, the I2S agenda could be relevant to all researchers still identifying with $\mathrm{OR}$, and not just those specializing in community-based applications.

The final paper in this special issue, by Johnson, Midgley, and Chichirau (2018), is our own summary of the emerging trends and new frontiers we see for Community OR. We look to the future, covering a broad range of opportunities, including how Community OR can contribute to disaster planning; the advent of analytics and its implications for Community OR; how Behavioral OR might inform our development of new and improved methodologies and methods; the interface between Community OR and urban planning; the use of information technologies and information systems; big (and difficult!) data; a Community OR lens on smart and resilient cities; diversity and inclusion; Community $\mathrm{OR}$ in developing countries and with indigenous people; and dealing with environmental issues. Of course this is an incomplete list, as many of the papers in this special issue show: collectively, they have already advanced the agenda of Community OR well beyond our own thinking.

\section{Conclusion}

In conclusion, we recommend this special issue to you. We believe that the combined understanding of practice represented in these papers has the capacity, not just to take forward the agenda of Community OR, but OR more generally. For decades people have been talking about the emergence of an "enhanced OR" (Jackson, 1987, 1988) or "engaged OR" (Midgley et al., 2018), and we believe it is time for this to be accepted as normal by the majority of practitioners. In an increasingly complex world, where so many organizational, social and environmental problems require practitioners to grapple with interconnectedness and multiple perspectives, nothing less than a fully engaged $O R$ (beyond just clients) makes sense. Community OR can lead the way in helping to show what this means.

We hope that this special issue inspires new practitioners to take up the banner of Community OR and make their own contributions, right across the world. If you personally are inspired, do not hesitate to get involved with the community concerns that matter to you most. Importantly, please 
write up your experiences for publication, and not just for scholarly outlets such as this one. Let us make sure the dialogue on Community OR continues to thrive!

\section{References}

Ackermann, F. (2012). Problem structuring methods 'in the dock': Arguing the case for 'soft OR'. European Journal of Operational Research, 219 , 652-658. doi: 10.1016/j.ejor.2011.11.014 .

Ackermann, F. , Bawden, R. , Bosch, O. , Brocklesby, J. , Bryant, J. , Buede, D. , et al. (2009). The case for soft O.R. OR/MS Today, 36 (2), 20-21.

Ackoff, R. L. (1970). A black ghetto's research on a university. Operations Research, 18 , 761-771. doi: 10.1287/opre.18.5.761 .

Ackoff, R. L. (1979a). The future of operational research is past. Journal of the Operational Research Society, 30 , 93-104. doi: 10.1057/jors.1979.22 .

Ackoff, R. L. (1979b). Resurrecting the future of operational research. Journal of the Operational Research Society, 30 (3), 189-199. doi: 10.2307/30 09600.

Alrøe, H. F. (20 0 0). Science as systems learning: Some reflections on the cognitive and communicational aspects of science. Cybernetics and Human Knowing, 7 (4), 57-78.

Bammer, G. (2018). Strengthening community operational research through exchange of tools and strategic alliances. European Journal of Operational Research, 268 (3), 1168-1177. doi: 10.1016/j.ejor.2017.09.041 .

Barros-Castro, R. A., Midgley, G., \& Pinzón, L. (2015). Systemic intervention for computer-supported collaborative learning. Systems Research and Behavioral Science, 32 (1), 86-105. doi: 10.1002/sres.2220

Beer, S. (1984). The viable system model: Its provenance, development, methodology and pathology. Journal of the Operational Research Society, $35,7-25$. doi: 10.1057/jors.1984.2 .

Bishop, R. (1996). Collaborative research stories: Whakawhanaungatanga . Palmerston North: Dunmore Press .

Bowen, K. , Cook, A. , \& Luck, M. (1984). The writings of Steve Cook . Birmingham: Operational Research Society .

Bradbury, H. (2015). The SAGE handbook of action research (3rd ed). London: Sage .

Brauer, T. (2018). Capturing the imprecision during an OR intervention: What is, what isn't and what should be. European Journal of Operational Research, 268 (3), 798-808. doi:

10.1016/j.ejor.2017.11.024 .

Brocklesby, J., \& Beall, E. (2018). Processes of engagement and methodology design in community operational research - Insights from the indigenous peoples sector. European Journal of Operational Research, 268 (3), 996-1005. doi: 10.1016/j.ejor.2017.07.053.

Brown, V. A. , Harris, J. A. , \& Russell, J. Y. (2010). Tackling wicked problems through the transdisciplinary imagination . Abingdon: Earthscan . 
Burns, D. (2018). Deepening and scaling participatory research with the poorest and most marginalised. European Journal of Operational Research, 268 (3), 865-874. doi:

10.1016/j.ejor.2017.11.025 .

Cabrera, D., Cabrera, L., Powers, E., Solin, J., \& Kushner, J. (2018). Applying systems thinking models of organizational design and change in community operational research. European Journal of Operational Research, 268 (3), 932-945. doi: 10.1016/j.ejor.2017.11.006.

Christakis, A. N. (1996). A people science: The CogniScope system approach. Systems: Journal of Transdisciplinary Systems Sciences, 1 (1), 16-19 .

Cook, S. L. (1973). Operational research, social well-being and the zero growth concept. Omega, 1 (6), 647-667. doi: 10.1016/0305-0483(73)90084- 4 .

Cracknell, B. E. (20 0 0). Evaluating development aid: Issues, problems and solutions . London: Sage .

Davenport, D. , \& Skandera, H. (2003). Civic associations. In P. Berkowitz (Ed.), Never a matter of indifference: Sustaining virtue in a free republic (pp. 59-83). Stanford, CA: Hoover Institution Press .

Espinosa, A., \& Duque, C. (2018). Complexity management and multi-scale governance: A case study in an Amazonian indigenous association. European Journal of Operational Research, 268 (3), 10061020. doi: 10.1016/j.ejor.2017.07.049 .

Fabusuyi, T. (2018). Is crime a real estate problem? A case study of the neighbourhood of East Liberty, Pittsburgh, Pennsylvania. European Journal of Operational Research, 268 (3), 1050-1061. doi: 10.1016/j.ejor.2017.12.003 .

Fazey, I., Schäpke, N., Caniglia, G., Patterson, J., Hultman, J., et al. (2018). Ten essentials for actionoriented and second order energy transitions, transformations and climate change research. Energy Research and Social Science, 40 , 54-70. doi: 10.1016/j.erss.2017.11.026.

Ferretti, V., \& Gandino, E. (2018). Co-designing the solution space for rural regeneration in a new World Heritage site: A choice experiments approach. European Journal of Operational Research, 268 (3), 1077-1091. doi: 10.1016/j.ejor.2017.10.003 .

Fildes, R. A., \& Ranyard, J. C. (1997). Success and survival of operational research groups: A review. Journal of the Operational Research Society, 48 (4), 336-360. doi: 10.1057/palgrave.jor .

Foote, J., Baker, V., Gregor, J., Hepi, M., Houston, D., \& Midgley, G. (2007). Systemic problem structuring applied to community involvement in water conservation. Journal of the Operational Research Society, 58 , 645-654. doi: 10.1057/palgrave.jors.2602248.

Gell-Mann, M. (1994). Complex adaptive systems. In G. Cowan, D. Pines, \& D. Meltzer (Eds.), Complexity: Metaphors, models, and reality (pp. 17-29). Reading, MA: Addison-Wesley .

Gomes, S. L., Hermans, L. M., \& Thissen, W. A. (2018). Extending community operational research to address institutional aspects of societal problems: Experiences from peri-urban Bangladesh. European Journal of Operational Research, 268 (3), 904-917. doi: 10.1016/j.ejor.2017.11.007.

Goulding, C., Kelemen, M., \& Kiyomiya, T. (2018). Community based response to the Japanese tsunami: A bottom-up approach. European Journal of Operational Research, 268 (3), 887-903. doi: 10.1016/j.ejor.2017.11.066. 
Gregory, A. J., \& Atkins, J. P. (2018). Community operational research and citizen science: Two icons in need of each other. European Journal of Operational Research, 268 (3), 1111-1124. doi:

10.1016/j.ejor.2017.07.037.

Gunderson, L. H. , \& Holling, C. S. (2002). Panarchy: Understanding transformations in human and natural systems. Washington DC: Island Press .

Helfgott, A. (2018). Operationalizing systemic resilience. European Journal of Operational Research, 268 (3), 852-864. doi: 10.1016/j.ejor.2017.11.056.

Heron, J., \& Reason, P. (1997). A participatory inquiry paradigm. Qualitative Enquiry, 3 (3), 274-294. doi: $10.1177 / 107780049700300302$.

Herron, R., \& Mendiwelso-Bendek, Z. (2018). Supporting self-organised community research through informal learning. European Journal of Operational Research, 268 (3), 825-835. doi:

10.1016/j.ejor.2017.08.009 .

Hindle, G. A., \& Vidgen, R. (2018). Developing a business analytics methodology: A case study in the foodbank sector. European Journal of Operational Research, 268 (3), 836-851. doi: 10.1016/j.ejor.2017.06.031 .

Irwin, A. (1995). Citizen science: A study of people, expertise and sustainable development . London: Routledge.

Jackson, M. C. (1987). Community operational research: Purposes, theory and practice. Dragon, 2 (2), 47-73 .

Jackson, M. C. (1988). Some methodologies for community operational research. Journal of the Operational Research Society, 39 (8), 715-724. doi: 10.2307/2583766 .

Jackson, M. C. (2004). Community operational research: Purposes, theory and practice. In G. Midgley, \& A. E. Ochoa-Arias (Eds.), Community operational research: OR and systems thinking for community development (pp. 57-74). New York: Kluwer. doi: 10.1007/978- 1- 4419- 8911- 6 _ 3 .

Johnson, M. P. (2012). Community-based operations research: Decision modeling for local impact and diverse populations. New York: Springer .

Johnson, M. P., Midgley, G., \& Chichirau, G. (2018). Emerging trends and new frontiers in community operational research. European Journal of Operational Research, 268 (3), 1178-1191. doi:

10.1016/j.ejor.2017.11.032 .

Johnson, M. P., \& Smilowitz, K. (2007). Community-based operations research. In T. Klastorin (Ed.), Tutorials in operations research 2007 (pp. 102-123). Hanover, MD: INFORMS. doi:

10.1287/educ.1073.0035 .

Jones, S., \& Eden, C. (1981). O.R. in the community. Journal of the Operational Research Society, 32 , 335-345. doi: 10.1057/jors.1981.71.

Keeney, R. L. (1996). Value-focused thinking: Identifying decision opportunities and creating alternatives. European Journal of Operational Research, 92 (3), 537-549. doi: 10.1016/03772217(96)0 00 04-5.

Keys, P. (1995). Understanding the process of operational research: Collected readings . Chichester: Wiley . 
Keys, P., \& Midgley, G. (2002). The process of OR. Journal of the Operational Research Society, 53 , 123-125. doi: 10.1057/palgrave.jor .

Konsti-Laakso, S., \& Rantala, T. (2018). Managing community engagement: A process model for urban planning. European Journal of Operational Research, 268 (3), 1040-1049. doi:

10.1016/j.ejor.2017.12.002 .

Laouris, Y., \& Michaellides, M. (2018). Structured democratic dialogue: An application of a mathematical problem structuring method to facilitate reforms with local authorities in Cyprus. European Journal of Operational Research, 268 (3), 918-931. doi: 10.1016/j.ejor.2017.04.039 .

Lewis, E. D. (2016). Gendered systemic analysis: Systems thinking and gender equality in international development. University of Hull PhD Thesis .

Liamputtong, P. , \& Rumbold, J. (2008). Knowing differently: Arts based and collaborative research methods. New York: Nova Science Publishers .

Liberatore, M. J., \& Luo, W. (2010). The analytics movement: Implications for operations research. Interfaces, 40 (4), 313-324. doi: 10.1287/inte.1100.0502 .

McEvoy, P., Brady, M., \& Munck, R. (2016). Capacity development through international projects: A complex adaptive systems perspective. International Journal of Managing Projects in Business, 9 (3), 528-545. doi: 10.1108/IJMPB- 08- 2015- 0072.

McKenna, R., Bertsch, V., Mainzer, K., \& Fichtner, W. (2018). Combining local preferences with multicriteria decision analysis and linear optimization to develop feasible energy concepts in small communities. European Journal of Operational Research, 268 (3), 1092-1110. doi:

10.1016/j.ejor.2018.01.036.

Merali, Y. (2006). Complexity and information systems: The emergent domain. Journal of Information Technology, 21 , 216-228. doi: 10.1057/palgrave.jit.20 00081 .

Midgley, G. (20 0 0). Systemic intervention: Philosophy, methodology, and practice . New York: Kluwer/Plenum .

Midgley, G. (2003). Systems thinking : volumes I-IV. London: Sage .

Midgley, G. (2008). Systems thinking, complexity and the philosophy of science. Emergence:

Complexity and Organization, 10 (4), 55-73. doi:

10.emerg/10.17357.a7ba7e7cf2ed80ce4517c6052dc486de .

Midgley, G., Ahuriri-Driscoll, A., Baker, V., Foote, J., Hepi, M., Taimona, H., et al. (2007). Practitioner identity in systemic intervention: Reflections on the promotion of environmental health through $\mathrm{M}$ -aori community development. Systems Research and Behavioral Science, $24,233-247$. doi: 10.1002/sres.827 .

Midgley, G., Cavana, R. Y., Brocklesby, J., Foote, J., Ahuriri-Driscoll, A., \& Wood, D. (2013). Towards a new framework for evaluating systemic problem structuring methods. European Journal of Operational Research, 229 , 143-154. doi: 10.1016/j.ejor.2013.01.047.

Midgley, G., Johnson, M. P., \& Chichirau, G. (2018). What is community operational research. European Journal of Operational Research, 268 (3), 771-783. doi: 10.1016/j.ejor.2017.08.014 . 
Midgley, G., Munlo, I., \& Brown, M. (1998). The theory and practice of boundary critique: Developing housing services for older people. Journal of the Operational Research Society, 49 , 467-478. doi: $10.2307 / 3009885$.

Midgley, G., \& Ochoa-Arias, A. E. (2004). An introduction to community operational research. In G. Midgley, \& A. E. Ochoa-Arias (Eds.), Community operational research: OR and systems thinking for community development (pp. 1-36). New York: Kluwer. doi: 10.1007/978- 1- 4419-8911- 6 _ 1.

Midgley, G., \& Pinzón, L. (2011). The implications of boundary critique for conflict prevention. Journal of the Operational Research Society, 62 , 1543-1554. doi: 10.1057/jors.2010.76.

Midgley, G. , \& Reynolds, M. (2001). Operational research and environmental management: A new agenda . Birmingham: Operational Research Society .

Midgley, G., \& Reynolds, M. (2004). Community and environmental OR: Towards a new agenda. In G. Midgley, \& A. E. Ochoa-Arias (Eds.), Community operational research: OR and systems thinking for community development (pp. 297-315). New York: Kluwer. doi: 10.1007/978- 1- 4419- 8911- 6 _ 13 .

Mingers, J. (2011a). Taming hard problems with soft O.R. OR/MS Today, 36 (2), 48-53 .

Mingers, J. (2011b). Soft OR comes of age - but not everywhere! Omega, 39 , 729-741. doi: 10.1016/j.omega.2011.01.005 .

Morgan, T. K. K. B., \& Fa'aui, T. N. (2018). Empowering indigenous voices in disaster response: Applying the mauri model to New Zealand's worst environmental maritime disaster. European Journal of Operational Research, 268 (3), 984-995. doi: 10.1016/j.ejor.2017.05.030 .

Mwiti, F., \& Goulding, C. (2018). Gender and strategies for community improvement: An ethnography of community based organizations ('Chamas') and women's interventions in the Nairobi slums. European Journal of Operational Research, 268 (3), 875-886. doi:

10.1016/j.ejor.2017.12.009 .

National Science Foundation (2018). Science and Engineering Doctorates: Table 13 -by subfield: 2006-16. Web: https://www.nsf.gov/statistics/2018/nsf18304/data/tab13.pdf [accessed 21 February 2018].

NORAD. (1999). The logical framework approach (LFA): Handbook for objectives-oriented planning (4th ed). Olso: NORAD .

Noad, N. , \& King, L. (1977). Area co-ordination: Some examples compared. Linkage, 2 , 10-13 .

Ochoa-Arias, A. E. (1994). The possibilities of Community OR in a third world country. International Transactions in Operational Research, 1 , 345-352. doi: 10.1016/0969- 6016(94)90034- 5 .

Ochoa-Arias, A. E. (2004). An interpretive systemic exploration of community action in Venezuela. In G. Midgley, \& A. E. Ochoa-Arias (Eds.), Community operational research: OR and systems thinking for community development (pp. 275-296). New York: Kluwer. doi: 10.1007/978- 1- 4419- 8911- 6 _ 12 .

Ormerod, R. J. (2014). The mangle of OR practice: Towards more informative case studies of 'technical' projects. Journal of the Operational Research Society, 65 (8), 1245-1260 .

Pinzón-Salcedo, L. A., \& Torres-Cuello, M. A. (2018). Community operational research: Developing a systemic peace education programme involving urban and rural communities in Colombia. European Journal of Operational Research, 268 (3), 946-959. doi: 10.1016/j.ejor.2017.11.040 . 
Rajagopalan, R., \& Midgley, G. (2015). Knowing differently in systemic intervention. Systems Research and Behavioral Science, 32 (5), 546-561. doi: 10.1002/sres.2352 .

Ranyard, J. C. (1997). Editorial. Journal of the Operational Research Society, 48 (1), 1-2. doi: 10.1057/palgrave.jors.2600369.

Ritchie, C. (2004). Housing in the Dearne Valley: doing Community OR with the Thurnscoe Tenants Housing Co-operative. In G. Midgley, \& A. E. Ochoa-Arias (Eds.), Community operational research: OR and systems thinking for community development (pp. 121-142). New York: Kluwer. doi: 10.1007/978- 1- 4419-8911- $6 \_6$.

Ritchie, C. , \& Taket, A. (1994). Operational research and community operational research - Some background. In C. Ritchie, A. Taket, \& J. Bryant (Eds.), Community works: 26 case studies showing community operational research in action (pp. 227-230). Sheffield: Pavic Press .

Rittel, H. W. J., \& Webber, M. M. (1973). Dilemmas in a general theory of planning. Policy Sciences, $4,155-169$. doi: 10.1007/BF01405730 .

Romm, N. R. A. (2001). Accountability in social research: Issues and debates . New York: Kluwer/Plenum .

Romm, N. R. A. (2015). Reviewing the transformative paradigm: A critical systemic and relational (indigenous) lens. Systemic Practice and Action Research, 28 (5), 411-427. doi: 10.1007/s11213-0159344-5 .

Romm, N. R. A. (2018). Reflections on a multi-layered intervention in the South African public education system: Some ethical implications for community operational research. European Journal of Operational Research, 268 (3), 971-983. doi: 10.1016/j.ejor.2017.02.022 .

Rosenhead, J. (1986). Custom and practice. Journal of the Operational Research Society, 37 (4), 335343. doi: $10.1057 /$ jors.1986.61.

Rosenhead, J. (1993). Enabling analysis: Across the developmental divide. Systems Practice, 6 (2), 117-138. doi: 10.1007/BF01062247.

Rosenhead, J. , \& Mingers, J. (2001). Rational analysis for a problematic world revisited: Problem structuring methods for complexity, uncertainty and conflict (2nd edition). Chichester: Wiley .

Shen, C.-Y., \& Midgley, G. (2007). Toward a Buddhist systems methodology 3: An application in a Taiwanese non-governmental organization. Systemic Practice and Action Research, 20 , 211-244. doi: 10.10 07/s11213-0 06-9060-2 .

Simchi-Levi, D. (2009). Not the appropriate outlet. OR/MS Today, 36 (2), 21.

Smith, L. T. (1999). Decolonizing methodologies: Research and indigenous peoples . London: Zed Books.

Sova, C. A., Helfgott, A., Chaudhury, A. S., Matthews, D., Thornton, T. F., \& Vermeulen, S. J. (2015). Multi-level stakeholder influence mapping: Visualizing power relations across actor levels in Nepal's agricultural climate change adaptation regime. Systemic Practice and Action Research, 28 , 383-409. doi: 10.1007/s11213-014- 9335-y .

Stephens, A. (2012). Feminist systems theory: Learning by praxis. Systemic Practice and Action Research, 25 (1), 1-14. doi: 10.1007/s11213-011-9212-x . 
Stephens, A. (2013). Ecofeminism and systems thinking . London: Routledge .

Taket, A. (1994). Starting from where I was: Working in a feminist collective. In C. Ritchie, A. Taket, \& J. Bryant (Eds.), Community works: 26 case studies showing community operational research in action (pp. 47-51). Sheffield: Pavic Press .

Taylor, K. C. (2018). Teaching decision-making and building resilience in youth -A case study to reduce the supply of vulnerable youth to sex traffickers in Atlanta, Georgia. European Journal of Operational Research, 268 (3), 960-970. doi: 10.1016/j.ejor.2017.11.067.

Thorsen, A., \& McGarvey, R. G. (2018). Efficient frontiers in a frontier state: Viability of mobile dentistry services in rural areas. European Journal of Operational Research, 268 (3), 1062-1076. doi: 10.1016/j.ejor.2017.07.062 .

Thunhurst, C. P. (2013). Public health systems analysis - where the River Kabul meets the River Indus. Globalization and Health, 9 (1), 39. doi: 10.1186/1744- 8603- 9- 39 .

Tirivanhu, P., Matondi, P. B., \& Sun, D. (2016). Systemic evaluation of a comprehensive community initiative based on boundary critique in Mhakwe ward in Zimbabwe. Systemic Practice and Action Research, 29 (6), 541-564. doi: 10.1007/s11213- 016- 9377- 4 .

Trist, E. L. , \& Burgess, S. (1978). Multiple deprivation: A human and economic approach. Linkage, 3 , $8-9$.

Ufua, D. E., Papadopoulos, T., \& Midgley, G. (2018). Systemic lean intervention: Enhancing lean with community operational research. European Journal of Operational Research, 268 (3), 1134-1148. doi: 10.1016/j.ejor.2017.08.004 .

Ulrich, W. (1993). Some difficulties of ecological thinking, considered from a critical systems perspective: A plea for critical holism. Systems Practice, 6 , 583-611. doi: 10.1007/BF01059480.

Ulrich, W. (1994). Critical heuristics of social planning: A new approach to practical philosophy . Chichester: Wiley .

Velez-Castiblanco, J., Brocklesby, J., \& Midgley, G. (2016). Boundary games: How teams of OR practitioners explore the boundaries of intervention. European Journal of Operational Research, 249 , 968-982. doi: 10.1016/j.ejor.2015.08.006.

Walsh, M., Kittler, M. G., \& Mahal, D. (2018). Towards a new paradigm of healthcare: Addressing challenges to professional identities through community operational research. European Journal of Operational Research, 268 (3), 1125-1133. doi: 10.1016/j.ejor.2017.05.052 .

Waltner-Toews, D., Kay, J., Murray, T. P., \& Neudoerffer, C. (2004). Adaptive methodology for ecosystem sustainability and health (AMESH): An introduction. In G. Midgley, \& A. E. Ochoa-Arias (Eds.), Community operational research: OR and systems thinking for community development (pp. 317-349). New York: Kluwer. doi: 10.1007/978- 1- 4419- 8911- 6 _ 14 .

Wang, Y., Touboulic, A., \& O'Neill, M. (2018). An exploration of solutions for improving access to affordable fresh food with disadvantaged Welsh communities. European Journal of Operational Research, 268 (3), 1021-1039. doi: 10.1016/j.ejor.2017.11.065.

Warfield, J. N. (1973). Participative methodology for public system planning. Computers \& Electrical Engineering, 1 (2), 187-210. doi: 10.1016/0045-7906(73)90014-1 . 
Weaver, M. W., Crossan, K., Tan, H. B., \& Paxton, S. E. (2018). A systems approach to understanding the perspectives in the changing landscape of responsible business in Scotland. European Journal of Operational Research, 268 (3), 1149-1167. doi: 10.1016/j.ejor.2017.11.050 .

White, L. (2018). A Cook's tour: Towards a framework for measuring the social impact of social purpose organizations. European Journal of Operational Research, 268 (3), 784-797. doi: 10.1016/j.ejor.2017.06.015 .

White, L. (2006). Evaluating problem-structuring methods: Developing an approach to show the value and effectiveness of PSMs. Journal of the Operational Research Society, 57 , 842-855. doi: 10.1057/palgrave.jors.2602149 .

White, L., Smith, H., \& Currie, C. (2011). OR in developing countries: A review. European Journal of Operational Research, 208 (1), 1-11. doi: 10.1016/j.ejor.2010.02.015 .

Womack, J. P. , \& Jones, D. T. (2003). Lean thinking: Banish waste and create wealth in your corporation (2nd ed). London: Simon and Schuster .

Yearworth, M., \& White, L. (2018). Spontaneous emergence of Community OR: Selfinitiating, selforganising problem structuring mediated by social media. European Journal of Operational Research, 268 (3), 809-824. doi: 10.1016/j.ejor.2018.01.024 . 